\title{
O perspectivismo nietzschiano como mecanismo para a transvaloração de todos os valores
}

\author{
Nietzschean perspectivism as a mechanism for the transvaluation of all \\ values
}

BIANCA SQUARISI ROQUE DE OLIVEIRA ${ }^{1}$

\begin{abstract}
Resumo: O presente texto busca demonstrar como a ideia de perspectivismo nietzschiano, já na forma que fora inserida na obra Humano, demasiado Humano I (antes mesmo do prefácio introduzido à obra posteriormente, em 1886) teria contribuído para a transvaloração de todos os valores. A fim defender que o perspectivismo fora utilizado por Nietzsche como um dos mecanismos de preparação de seu leitor para o projeto central de sua filosofia: a transvaloração de todos os valores, faz-se necessário salientar que o projeto central da filosofia nietzschiana já se constituía como objetivo filosófico de Nietzsche décadas antes da primeira aparição do termo "transvaloração" em uma obra publicada.

Palavras-chave: Perspectivismo. Nietzsche. Transvaloração.
\end{abstract}

Abstract: The present text tries to demonstrate how the idea of Nietzschean perspectivism, already in the form that was inserted in the Human, too Human I (before the preface later introduced in 1886) would have contributed to the transvaluation of all values. In order to defend that perspectivism was used by Nietzsche as one of the mechanisms of preparation of his reader for the central project of his philosophy. Is the transvaluation of all values, it is necessary to point out that the central project of Nietzsche's philosophy was already constituted as philosophical objective of Nietzsche decades before the first appearance of the term "transvaluation" in a published work.

Keywords: Perspectivism. Nietzsche. Transvaluation.

\section{Introdução}

O perspectivismo nietzschiano, como o estudamos, é fruto de uma extração dos termos e ideias perspectivísticas ligadas ao termo "perspectivismo" apresentado por Nietzsche em poucas passagens de toda sua obra. Apesar de poucas aparições do termo "perspectivismo" na obra do filósofo, a ideia inserida a partir deste termo permeia toda sua filosofia e serve como base de apoio para diversas críticas efetivadas. No entanto, Nietzsche não determina de forma categórica seu perspectivismo, restando aos pesquisadores e comentadores da filosofia nietzschiana efetuar esta extração de sentidos em diversos momentos da obra em que a ideia de perspectiva se apresenta.

\section{Perspectivismo}

A ideia do que denominamos "perspectivismo nietzschiano", ou seja, perspectivismo como Nietzsche concebe e aplica à sua filosofia, pode ser encontrada

\footnotetext{
${ }^{1}$ Universidade Estácio de Sá. E-mail: biancasquarisi@gmail.com.
} 
em textos anteriores à primeira aparição do termo "perspectivismo" na obra (1886). Neste trabalho pretendemos demonstrar como Nietzsche se utilizou da ideia de perspectivismo já na obra Humano, demasiado Humano I, publicada em 1878.

Percebemos a presença da ideia de perspectiva aplicada aos questionamentos filosóficos na obra de Blaise Pascal, de quem Nietzsche era leitor. Entretanto, Pascal restringe sua análise perspectivista para o âmbito epistemológico, enquanto que Nietzsche amplia a noção de perspectiva e a insere em diferentes campos de questionamentos filosóficos.

Apesar de pretendermos demonstrar a presença e utilização da ideia de perspectiva desde Humano, demasiado Humano I, o termo e a máxima pela qual se entende expressa a ideia de perspectivismo nietzschiano só aparecem em publicações do ano de 1886. No prólogo da obra Para Além de Bem e Mal (1886), Nietzsche insere a perspectiva como "condição básica de toda vida" e apresenta a máxima "Não existem fenômenos morais, apenas uma interpretação moral dos fenômenos..." (NIETZSCHE, BM, §108, 2005, p. 66). Da mesma forma, no prefácio que insere à obra Humano, demasiado Humano I no ano de 1886 , afirma que os valores são sempre constituídos por estimativas perspectivísticas, que traduzem as condições de conservação e intensificação de determinadas espécies de vida.

Conforme nos ensinam Pietro Gori e Paolo Stellino, podemos constatar a presença de um perspectivismo gnoseológico e um perspectivismo moral na obra de Nietzsche. À nossa análise interessa deter-nos ao âmbito da moral. Nas palavras de Gori e Stellino

Como pensa para o caso da verdade, segundo Nietzsche o caráter moral de uma ação não pertence intrinsecamente a ela mesma, não se trata de um em si, mas deriva de uma sucessiva interpretação do ocorrido. Uma mesma ação pode, dessa forma, pode obter muitas interpretações morais, cada uma delas depende da perspectiva assumida por quem a julga, mas nenhuma delas podendo valer em sentido absoluto. Com efeito, cada avaliação (Wertschätzung) consiste em avaliar (schätzen) o valor (Wert) de alguma coisa, e tal avaliação é sempre emitida segundo uma determinada perspectiva. (GORI e STELLINO, CN n. 34, vol. I, 2014, p. 106)

Para Nietzsche, portanto, os fatos em si são destituídos de valor moral, mas somos nós - os viventes, que atribuímos ao mundo e aos fatos, valores morais de acordo com a perspectiva utilizada ou vigente em uma determinada época.

A fim de demonstrar a utilização da ideia de perspectivismo, apresentada em Humano, demasiado Humano I (1878), como um mecanismo aplicado à transvaloração de todos os valores, algumas considerações se fazem necessárias, para fins de contextualização temporal dos empenhos filosóficos de Nietzsche. Cumpre esclarecer que, apesar do termo "transvaloração" aparecer, pela primeira 
vez, numa obra publicada por Nietzsche, em 1886, Para Além de Bem e Mal, já no texto "Fado e História" de 1862, Nietzsche se referia a necessidade de não somente criticar, mas de "encontrar um ponto de vista mais livre, onde se possa lançar sobre a religião e o cristianismo um julgamento imparcial e adaptado à própria época" (NIETZSCHE, GM, 2009 p. 153), assim como reconhece em Crepúsculo dos Ídolos (1888) ter efetivado uma transvaloração de valores já em O Nascimento da Tragédia, publicado em 1872 .

O dizer Sim à vida, mesmo em seus problemas mais duros e estranhos; a vontade de vida, alegrando-se da própria inesgotabilidade no sacrifício de seus mais elevados tipos - a isso chamei dionisíaco, nisso vislumbrei a ponte para a psicologia do poeta trágico. Não para livrar-se do pavor e da compaixão, não para purificar-se de um perigoso afeto mediante sua veemente descarga assim o compreendeu Aristóteles - mas para, além do pavor e da compaixão, ser em si mesmo o eterno prazer do vir-a-ser - esse prazer que traz em si também o prazer no destruir... E com isso todo novamente no ponto do qual uma vez parti - o Nascimento da tragédia foi minha primeira tresvaloração de todos os valores: com isso de volta ao terreno em que medra meu querer, meu saber - eu, o último discípulo do filósofo Dionísio - eu, o mestre do eterno retorno... (NIETZSCHE, CI, "O que devo aos antigos", §5, 2017, p. 90).

Feitas estas observações, estamos em condições de sustentar que, apesar do termo "transvaloração" surgir dentro da obra nietzschiana apenas em 1886, seu projeto filosófico já projetava e efetivava transvaloração de valores. Isto posto, passamos a demonstrar como Nietzsche insere e se vale da ideia de perspectivismo como um meio, uma preparação tanto do leitor, quanto da própria construção de seu pensamento filosófico, a fim de alcançar o objetivo de realizar uma transvaloração de todos os valores vigentes.

Em razão do alto grau de impacto e complexidade da tarefa, a transvaloração de todos os valores, foi sendo construída e apresentada por partes, executada através de mecanismos. Um destes mecanismos, teria sido, conforme pretendemos demonstrar e defender neste texto, a ideia de perspectivismo apresentada em Humano, demasiado Humano I (1878).

Neste ponto, nos impõe a tarefa de elucidar, de forma sintética, o que viria a ser a transvaloração de todos os valores proposta por Nietzsche. Sabemos que ela [a transvaloração] consiste em seu projeto filosófico central - como ele mesmo descreve em Ecce Homo.

Feitas estas observações, estamos em condições de sustentar que, apesar do termo "transvaloração" surgir dentro da obra nietzschiana apenas em 1886, seu projeto filosófico já projetava e efetivava transvaloração de valores. Isto posto, passamos a demonstrar como Nietzsche insere e se vale da ideia de perspectivismo 
como um meio, uma preparação tanto do leitor, quanto da própria construção de seu pensamento filosófico, a fim de alcançar o objetivo de realizar uma transvaloração de todos os valores vigentes.

Em razão do alto grau de impacto e complexidade da tarefa, a transvaloração de todos os valores, foi sendo construída e apresentada por partes, executada através de mecanismos. Um destes mecanismos, teria sido, conforme pretendemos demonstrar e defender neste texto, a ideia de perspectivismo apresentada em Humano, demasiado Humano I (1878).

Neste ponto, nos impõe a tarefa de elucidar, de forma sintética, o que viria a ser a transvaloração de todos os valores proposta por Nietzsche. Sabemos que ela [a transvaloração] consiste em seu projeto filosófico central - como ele mesmo descreve em Ecce Homo.

Para a tarefa de uma tresvaloração dos valores eram necessárias talvez mais faculdades do que as que jamais coexistiram num só indivíduo, sobretudo também antíteses de faculdades, sem as quais estas se poderiam obstruir, destruir. Hierarquia das faculdades; distância; a arte de separar sem incompatibilizar; nada misturar, nada "conciliar"; uma imensa multiplicidade, que no entanto é o contrário do caos - esta foi a precondição, a longa e secreta lavra e arte de meu instinto. (NIETZSCHE, EH, "Por que sou tão inteligente”, §9, 2008, p. 46).

Tomando por base ensinamentos do professor Luís Rubira, podemos afirmar que a transvaloração é compreendida por Nietzsche como a tarefa que visa à destruição do valor a partir do qual todos os valores do homem moderno foram engendrados: a moral judaico-cristã. Nietzsche observa que o valor (peso atribuído para valorar) sofreu uma mudança radical em sua estrutura, uma inversão, a partir do símbolo de "Cristo na cruz" e o advento do cristianismo. Essa inversão, que colocou "Deus" como novo peso para considerar os valores, bem como como a crença em verdades transcendentes, levou o homem à um niilismo, ou seja, uma desvalorização dos valores, uma negação do vir-a-ser e, portanto, da própria vida.

Porém, o niilismo encontra-se numa interpretação bem determinada, na interpretação cristã-moral. Em si mesma, a penúria, mesmo a penúria psíquica, física, intelectual, ainda não é inteiramente capaz de produzir niilismo, isto é, a recusa intransigente do valor, do sentido, da desejabilidade. (NIETZSCHE, FP do outono de 1885 ao outono de 1886, n. 2, KSA, vol. 12, p. 125).

De acordo com Rubira, o autor de Ecce Homo (obra tida por Nietzsche como um prólogo da transvaloração de todos os valores), "pensa então a transvaloração como o machado que servirá para cortar pela raiz a necessidade metafísica do ser humano [...] trata-se, portanto, não somente de uma prática de destruição e ultrapassamento dos valores oriundos do cristianismo, o platonismo para o povo, e 
da filosofia, compreendida em seu conjunto como movimento niilista, mas de todos os valores humanos, posto que Nietzsche visa a destruição e ao ultrapassamento do próprio fenômeno que sempre se manifestou em todas as épocas, povos e lugares: a moral”. (RUBIRA, Dicionário Nietzsche, 2016, p. 400 e 401).

Desta forma, Nietzsche pretende destruir o peso utilizado para consideração de valores: a moral judaico-cristã e sua consequente negação da vida. Mas, além de destruir, pretende alterar - estabelecer novo peso para valorar valores.

Feitas essas ponderações, passamos a demonstrar como Nietzsche se vale da inserção da ideia de perspectivismo em Humano, demasiado Humano I, como um mecanismo de questionamento do caráter absoluto dos valores morais engendrados na sociedade pelo cristianismo.

Já no aforismo 42, coloca em questão a ótica perspectiva do momento histórico-cultural em que o ente está inserido, desta forma afirma

A hierarquia dos bens não é fixa e igual em todos os tempos; quando alguém prefere a vingança à justiça, ele é moral segundo a medida de uma cultura passada, imoral segundo a atual [...] a própria hierarquia dos bens não é estabelecida ou alterada segundo pontos de vistas morais; mas com base na sua determinação vigente é decidido se uma ação é moral ou imoral. (NIETZSCHE, HH, §42, 2005, p. 47).

E continua se utilizando da ideia de perspectivismo para questionar a moral, tanto que no aforismo 81 chega a afirmar

Quando um homem rico toma um bem ao pobre (por exemplo, príncipe rouba a amada ao plebeu), produz-se um engano no pobre; ele acha que o outro deve ser um infame, para tomar-lhe o pouco que tem. Mas o outro não percebe tão profundamente o valor de um determinado bem, pois está acostumado a ter muitos; por isso não é capaz de se pôr no lugar do pobre, e de modo algum lhe faz tanta injustiça como ele crê. [...] Já o sentimento hereditário de ser alguém superior, com pretensões superiores, torna a pessoa fria e deixa a consciência tranquila: nada percebemos de injusto, quando a diferença entre nós e o outro ser é muito grande, e matamos um mosquito, por exemplo, sem qualquer remorso. (NIETZSCHE, HH, $\S 81,2005$, p. 62 e 63).

No aforismo 104, chega a utilizar a perspectiva da criança em sua inocência, para questionar o valor "mal", afirma

Quando não sabemos o mal que faz uma ação, ela não é uma ação maldosa; a criança não é maligna e nem perversa com os animais: ela os investiga e os destrói como um brinquedo. (NIETZSCHE, HH, §104, 2005, p. 74). 
Apesar do impacto que tais afirmações possam causar, entendemos que ao fazer tais provocações ao leitor, Nietzsche pretende demonstrar que o que quer que tenha valor no mundo, não tem valor em si, a coisa em si é isenta de valor, somos nós [humanos] que atribuímos valor às coisas e às ações de acordo com a perspectiva adotada. Assim, o filósofo insere sua ideia de perspectivismo moral que os valores morais atribuídos às ações não passam de interpretações por pontos de vista histórico, social, individual e, como viria a defender nas obras da maturidade, de interpretações movidas por nossos impulsos.

\section{Conclusão}

Estamos em condições de concluir que desde Humano, demasiado Humano I, a ótica perspectivista foi sendo inserida por Nietzsche como um mecanismo de questionamento dos valores morais, a fim de preparar o seu leitor ao grande projeto de sua filosofia: a transvaloração de todos os valores.

\section{Referências}

F MARTON, S. Nietzsche, das forças cósmicas aos valores humanos. 3. ed. Belo Horizonte: UFMG, 2010. Capítulo VI.

MARTON, S. (Org.). Dicionário Nietzsche. São Paulo: Loyola (Sendas \& veredas), 2016.

NIETZSCHE, F. W. Humano, demasiado humano: um livro para espíritos livres. Trad. Paulo César de Souza. São Paulo: Companhia de Bolso: 2005.

. Além do bem e do mal: prelúdio a uma filosofia do futuro. Trad. Paulo César de Souza. São Paulo: Companhia de Bolso: 2005.

. Genealogia da moral: uma polêmica. Trad. Paulo César de Souza. São Paulo:

Companhia de Bolso: 2009.

. Ecce Homo: como alguém se torna o que é. Trad. Paulo César de Souza. São Paulo: Companhia de Bolso: 2008.

Crepúsculo dos Ídolos, ou como se filosofa com o martelo. Trad. Paulo César de Souza. São Paulo: Companhia de Bolso: 2017.

GORI, P; STELLINO, P. O perspectivismo moral nietzschiano. Cad. Nietzsche, São Paulo, n. 34 - vol. I, p. 101-129, 2014.

RUBIRA, L. Nietzsche: do eterno retorno do mesmo à transvaloração de todos os valores. São Paulo: Barcarolla, Discurso, 2010.

Submissão: 01.10.2018 / Aceite: 30.11.2018. 